\title{
Connecting your radiology learning to your clinical practice: using personal learning environments, learning portfolios and communities of practice
}

\author{
Michael P. D’Alessandro
}

(C) Springer-Verlag 2011

\section{Introduction}

Continuing medical education, which is traditionally delivered in a format disconnected from clinical practice, has been found to be completely ineffective. The long-held dream of a few educational visionaries was to connect continuing medical education to clinical practice but this was technically difficult before the advent of the Internet. Today, this dream can become reality as the Internet can deliver the library of medical knowledge to the point-of-care. Furthermore, this dream has been endorsed by recent studies published by the Accreditation Council for Continuing Medical Education, the Josiah Macy Foundation and the Carnegie Foundation, which have stated that continuing medical education must be connected to clinical practice in order to change physicians' knowledge, attitudes and behaviors and to best improve patient care, outcomes and lives. Unfortunately, today most physicians do not know how to connect their learning to their practice. The purpose of this presentation is to show you how to connect your learning to your practice and to receive continuing medical education for it using personal learning environments, learning portfolios and communities of practice.

\section{Methods}

Definitions
Personal learning environment
A system that helps learners take control of and manage their own
Disclaimer Dr. D'Alessandro has no financial interests, investigational or off-label uses to disclose.

M. P. D’Alessandro $(\square)$

University of Iowa,

Iowa City, IA 52242, USA

e-mail: michael-dalessandro@uiowa.edu learning. This includes providing support for learners to set their own learning goals, manage their own learning in terms of both content and process and communicate with others in the process of learning and thereby achieve their learning goals.

Learning portfolio A record of a physician's personal learning experience. Each entry in the learning portfolio contains a clinical question, the patient's story, the answer, the impact on practice and the resources used to answer that question.

Community of practice

E-memory system A group of people who share a concern, a set of problems or a passion about a topic and who deepen their understanding of this area by interacting on an ongoing basis.

A system that captures, stores, organizes and makes retrievable your experience and reflected wisdom.

Web sites used

www.searchingradiology.com-a radiology-specific Google custom search engine

www.searchingpediatrics.com-a pediatric-specific Google custom search engine

myrsna.rsna.org-where one can receive CME credit for looking up the answers to clinical questions www.pediatriceducation.org — a pediatrician's learning portfolio over 5 years

www.pediatriccommons.org - a pediatric community of practice 


\section{Results}

Evaluation of medical learning portfolios shows that over time, an unstructured curriculum unfolds in practice with the learner taking control of and assuming responsibility for his or her own learning by tying learning to practice and receiving CME credit for it. Furthermore, there is a growing body of evidence that social networking technologies will bring positive changes to education, in and out of the classroom.

\section{Conclusion}

A personal learning environment helps learners take control of and manage their own learning. By entering cases into a learning portfolio you store your experience, reflection, knowledge and wisdom and create your own knowledge management and E-memory system. Furthermore, by participating in a community of practice where you contribute content, engage in conversations and make connections you are enabling peer-to-peer and master-toapprentice teaching. In the future it is hoped that tying your learning to your practice and being awarded continuing medical education credit for it will fulfill a larger role in the process of Maintenance of Certification and Continuing Professional Development.

Please feel free to join a prototype of this educational vision at Pediatric Commons (http://www.pediatriccommons.org), a community of pediatric learning, teaching, sharing and collaboration.

The latest version of this presentation may be found on Slideshare at http://www.slideshare.net/michaeldalessandro. 